\title{
Capillary Penetration between Dissimilar Solids ${ }^{1}$
}

\author{
W. J. O'BRIEN, R. G. CRAIG, AND F. A. PEYTON \\ School of Dentistry, Marquette University, Milwaukee, Wisconsin, and University of Michigan, \\ Ann Arbor, Michigan \\ Received October 2, 1967 \\ (See page 507 for Summary)
}

The mathematical formulas derived by Young and Laplace (1) cannot be readily applied to the penetration of a liquid between dissimilar solids. Their equation,

$$
h=\frac{2 \gamma_{L V}}{d g r},
$$

requires a knowledge of the radius of curvature of the liquid meniscus. Since the radius of curvature of the meniscus in the case of heterogeneous capillary spaces changes from point to point, it is extremely difficult to define $(2,3)$.

Mathematical Model. In preference to the curvature approach, the thermodynamic method recently emphasized by Schwartz and Minor (4) was employed. Consider the heterogeneous capillary space shown in Fig. 1. The width of the plates is chosen as one centimeter in order to simplify the calculations of interfacial area. The decrease in surface free energy realized by rajsing a differential element $d h$ to a level $h$ may be expressed as the change in surface free energy per unit area multiplied by the area $d A$ of the solid-liquid interface:

$$
\begin{array}{r}
d F=\left(F_{S V}-F_{S L}\right)_{1} d A_{1} \\
+\left(F_{S V}-F_{S L}\right)_{2} d A_{2} .
\end{array}
$$

It is necessary to treat the two solid-liquid interfaces separately since they have dif-

1 This research was supported in part by USPHS grant DE-1057 from the National Institute of Dental Research, National Institutes of Health, Bethesda, Maryland, of Marquette University. This report represents a portion of a thesis submitted in partial fulfillment by W. J. O'Brien for the degree of Doctor of Philosophy, H. H. Rackham School of Graduate Studies, University of Michigan, Ann Arbor, Michigan. ferent properties. The Young-Dupré equation gives

$$
\left(F_{S V}-F_{S L}\right)=\gamma_{L V} \cos \theta .
$$

Here $\gamma_{L V}$ refers to surface tension of the liquid, $\theta$ is the liquid-solid contact angle, $F_{\text {SV }}$ is the solid-vapor surface free energy per unit area, and $F_{S L}$ is the solid-liquid interfacial free energy per unit area. We may write

$$
\begin{aligned}
d F=\gamma_{L V} & \cos \theta_{1} 1 d h_{1} \\
& +\gamma_{L V} \cos \theta_{2} 1 d h_{2} .
\end{aligned}
$$

Since $d h_{1}$ equals $d h_{2}$,

$$
d F=\gamma_{L V}\left(\cos \theta_{1}+\cos \theta_{2}\right) d h .
$$

This may be equated to the increase in gravitational free energy accompanying this rise when equilibrium is reached.

$\gamma_{L V}\left(\cos \theta_{1}+\cos \theta_{2}\right) d h$

$$
=(d h)(b)(d)(h)(g) \text {. }
$$

Here the terms $b, d, h$, and $g$ denote the distance between the plates, the density of the liquid, the height of the differential element, and the gravitational constant, respectively. Dividing both sides by $d h$ and solving for $h$, we obtain

$$
h=\frac{\gamma_{L V}\left(\cos \theta_{1}+\cos \theta_{2}\right)}{(b)(d)(g)} .
$$

This is the capillary equation for a liquid rising between dissimilar plates. If both contact angles are equal, the equation simplifies to

$$
h=\frac{2 \gamma \cos \theta}{(b)(d)(g)}
$$




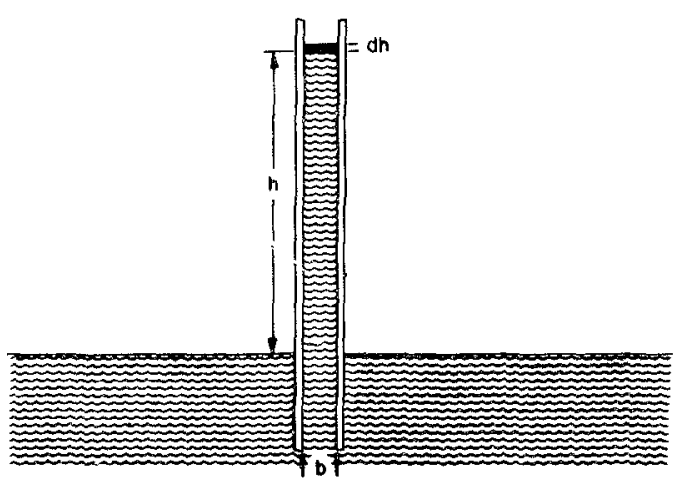

FIg. 1. Capillary rise between dissimilar parallel plates.

which is in complete agreement with that derived by the Young-Laplace approach. However, it is important to note that no consideration was given to the curvature of the meniscus. Also, the newly obtained prime equation has been derived with the proviso that the amount of liqud in the meniscus is insignificant. This stipulation is also made in the derivation of the YoungLaplace equation and has been found to hold as long as the capillary space is small. In the case of relatively wide capillary tubes, the size of the meniscus cannot be neglected. Modern interpretation of capillary phenomena favors the surface energy approach applied in the present derivation of this equation. However, the "surface tension" concept also lends itself toward the development of such a relationship. Consider the weight of liquid held up in a capillary space by the vertical components of surface tension of the liquid for plates $1 \mathrm{~cm}$ wide:

$$
\gamma_{L V} \cos \theta_{1}+\gamma_{L V} \cos \theta_{2}=h b d g .
$$

Solving for $h$, one obtains

$$
h=\frac{\gamma_{L V}\left(\cos \theta_{1}+\cos \theta_{2}\right)}{b d g} .
$$

Again, the mathematical identity of the approaches of surface free energy and surface tension is indicated.

When the plates comprising the capillary space are inclined at an angle to each other, additional terms may be introduced. If $b$ is the distance between the inclined plates as shown in Fig. 2, the following relation may be derived (5):

$$
b=2 x \tan \theta / 2 .
$$

Here $x$ is the horizontal distance from the vertex and $\phi$ is the angle between the plates.

Substituting this expression in the prime equation, [7], one obtains

$$
h=\frac{\gamma_{L V}\left(\cos \theta_{1}+\cos \theta_{2}\right)}{2 d g x \tan \phi / 2} .
$$

The equation of the hyperbola described by the surface of the liqud is then

$$
h x=K,
$$

and from Eq. [11] this is found to be

$$
h x=\frac{\gamma_{L V}\left(\cos \theta_{1}+\cos \theta_{2}\right)}{2 d g \tan \phi / 2}=K .
$$

Dimensional Analysis. To check the homogeneity of the newly derived equation for the capillary penetration between dissimilar plates inclined at an angle with each other, we first reduce it to fundamental units of mass, time, and length. Since $\gamma=M T^{-2}$, $d=M L^{-3}, g=L T^{-2}, x=L, \theta=0$, and $h=L$, we may write for Eq. [13]

$$
L=\frac{\left(M T^{-2}\right) 0}{\left(M L^{-3}\right)\left(L T^{-2}\right)(L)(0)},
$$

or

$$
L=L \text {. }
$$

This check gives an indication of the consistency of the derived equation with respect to its dimensions.

\section{MATERIALS AND METHODS}

Experimental Design. In a factorial design, permutations of treatments are examined. Several levels of one factor are crisscrossed with several levels of another. The factors to be introduced in the present research are: wetting of solid 1 , wetting of solid 2 , and the surface tension of the liquid. Therefore there are three factors. The factorial design used is shown in Table I. The yield or effect to be obtained in this experiment is an estimate of capillary rise or pressure. In order to reduce the error variance, the aforementioned hyperbola method was chosen (5). An average product of distance from the vertex $x$ and the capillary rise $h$ at that 


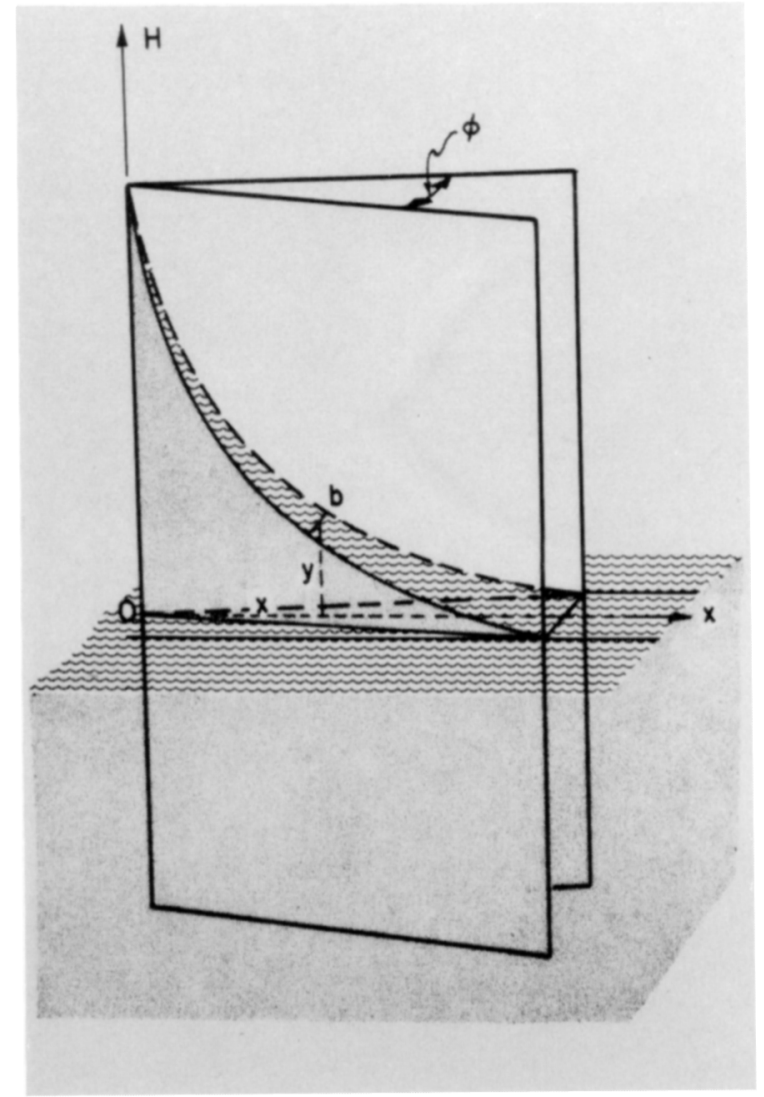

FIg. 2. Capillary rise between plates at an angle

TABLE I

Factorial Design Table for Capiliaky Rise Experiments

\begin{tabular}{|c|c|c|c|c|c|c|c|c|c|}
\hline \multicolumn{4}{|c|}{ Water } & \multicolumn{3}{|c|}{ Iodobenzene } & \multicolumn{3}{|c|}{ Ethanol } \\
\hline Glass & Teflon & Acrylic & Silicane & Glass & Teflon & Acrylic & Glass & Teffon & Acrylic \\
\hline \multicolumn{10}{|c|}{ Glass } \\
\hline$G-W-G$ & $\mathrm{G}-\mathrm{W}-\mathrm{T}$ & G-W-A & G-W-S & G-I-S & G-I-T & G-I-A & G-E-G & $\mathrm{G}-\mathrm{E}_{-}-\mathrm{T}$ & $\mathrm{G}-\mathrm{E}-\mathrm{A}$ \\
\hline \multicolumn{10}{|c|}{ Acrylic } \\
\hline$A-W-G$ & $A-W-T$ & $A-W-A$ & $A-W-S$ & $A-I-G$ & $A-I-T$ & $A-I-A$ & A-E-G & A-E-T & A-E-A \\
\hline
\end{tabular}

distance was chosen as an estimate of the yield. Therefore the error variance was reduced by a factor of $n^{1 / 2}$, when $n$ was the number of data points per hyperbola. In order to increase the numerical differences between the treatment combinations, materials and liquids with widely different surface energy values were chosen. The span in surface tension between ethanol and water is about 50 dynes $/ \mathrm{cm}$. The range of differences in contact angle values on the solids is about $95^{\circ}$.
It was hoped that all these measures would contribute toward a wider basis of inference, the specific aim being the evaluation of the newly derived mathematical model for the penetration of liquids between dissimilar solids.

Measurement of Parameters. Contact angles. The inclined plate method was used to measure the advancing and receding contact angles. This method has been developed by Macdougall and Ockrent (6). A drop of the liquid was placed on the solid in the hori- 


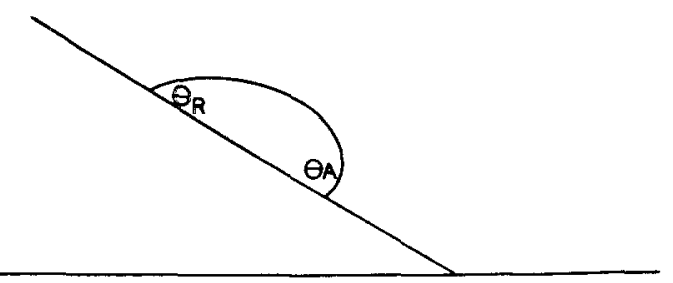

Fig. 3. Advancing and receding contact angles on a tilted plate.

zontal position. Then the solid specimen was rotated until the drop was just about to roll down the solid surface. Figure 3 depicts the drop at this point. A measurement was then made of the advancing and receding angles by means of a coordinate cathetometer with a protractor eyepiece on the telemicroscope. ${ }^{2}$ The specimens were contained within a temperature-controlled cabinet maintained at a temperature of $27^{\circ} \mathrm{C}$ and a relative humidity of approximately $70 \%$. A tilting micromanipulator ${ }^{3}$ was used to tilt the specimens, as shown in Fig. 4.

The liquids used were double distilled water, reagent grade iodobenzene $\mathrm{e}^{4}$ and absolute ethanol. ${ }^{5}$ Solids on which the liquids were placed were acrylic resin, ${ }^{6}$ Teflon, ${ }^{6}$ polished glass cleaned with dichromate solution, ${ }^{7}$ and silicone-treated glass. ${ }^{8}$

Surface tension. The ring method was used to determine the surface tensions of the liquids. This method has been widely employed and involves the measurement of the force to detach a platinum ring from the surface of the liquid by means of a torsion balance. ${ }^{9}$ The instrument was calibrated

${ }^{2}$ Model 1238-1818 Cathetometer, Gaertner Scientific Corp., Chicago, Illinois.

${ }^{3}$ Tilting micromanipulator, Sobotka Inc., New York, New York.

"Iodobenzene, Eastman Organic Chemicals, Rochester, New York.

${ }^{5}$ Absolute ethyl alcohol, reagent quality, U.S. Industrial Chemicals Corporation, New York, New York.

${ }^{6}$ Extruded acrylic sheet and Teflon sheet, Cadillac Plastics Co., Detroit, Michigan.

${ }^{7}$ Polished Pyrex Plate glass, Fred S. Hickey Corp., Schiller Park, Illinois.

${ }^{8}$ Desicote Silicone Coating, Beckman Instrument Co., California.

${ }^{9}$ Surface Tension Balance, Model No. 1396, A. Kruss Co., Hamburg, Germany. over the range with weights and a correction factor supplied by the instrument maker was employed to take into account the fact that surface tension did not pull vertically on the ring.

Capillary rise. The hyperbola method was used to measure capillary rise. Two plates each $10 \mathrm{~cm}$ by $14 \mathrm{~cm}$ were clamped together so as to make a small angle with each other by inserting a shim between them at one end. Steel shims $5 \mathrm{~mm}$ wide and with thicknesses of $0.5,0.75$, and 1.0 $\mathrm{mm}$ were used. They were cleaned with ethanol. The plates were secured in position by three rubber bands and held in a vertical position by means of a ringstand clamp. The combinations of materials and liquids used are shown in Table I. In order to improve the flatness of the Teflon plates, they were bonded to plate glass by means of an epoxy adhesive.

The assembly of two plates separated at one edge by means of a shim, was lowered into the liquid. The constant-temperature cabinet was then closed and the system allowed to come to equilibrium. The afore-

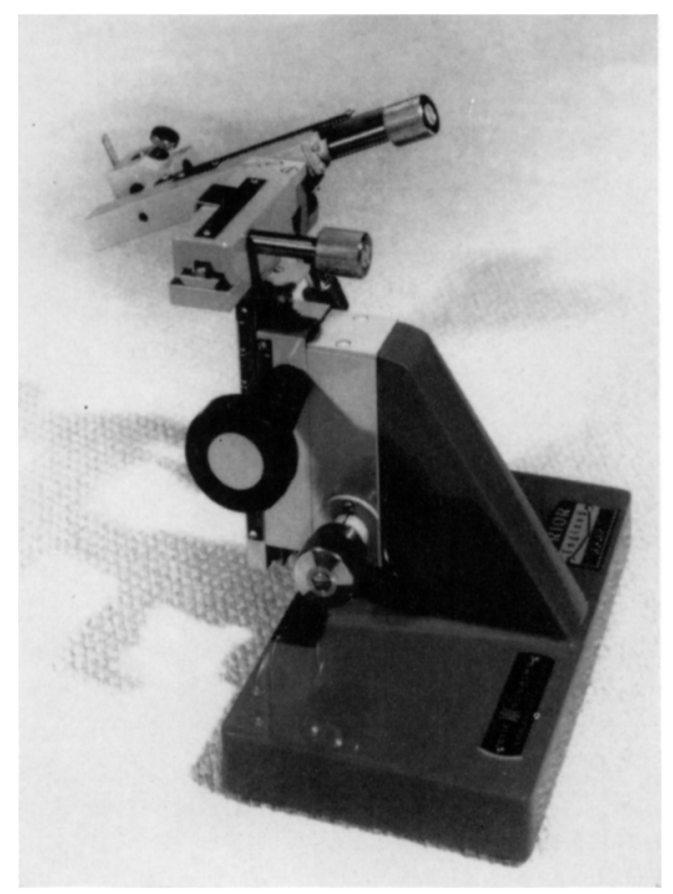

FIG. 4. Micromanipulator used for contact angle measurements. 
TABLE II

Contact Angles of Liquids on Various Solids AT $27^{\circ} \mathrm{C}$

\begin{tabular}{l|l|c|c|c}
\hline \multicolumn{1}{c|}{ Solid } & \multicolumn{1}{|c|}{ Liquid } & $\begin{array}{c}\theta_{A} \\
(\text { degrees })\end{array}$ & $\begin{array}{c}\theta_{R} \\
(\text { degrees })\end{array}$ & $n$ \\
Acrylic & Water & 74 & 54 & 5 \\
Teflon & Water & 110 & 82 & 4 \\
Glass & Water & 14 & 11 & 6 \\
Desicote & Water & 91 & 65 & 6 \\
Acrylic & Ethanol & Spreads & & 3 \\
Teflon & Ethanol & 29 & 16 & 7 \\
Glass & Ethanol & Spreads & & 3 \\
Acrylic & Iodobenzene & 20 & 12 & 7 \\
Teflon & Iodobenzene & 59 & 31 & 3 \\
\hline
\end{tabular}

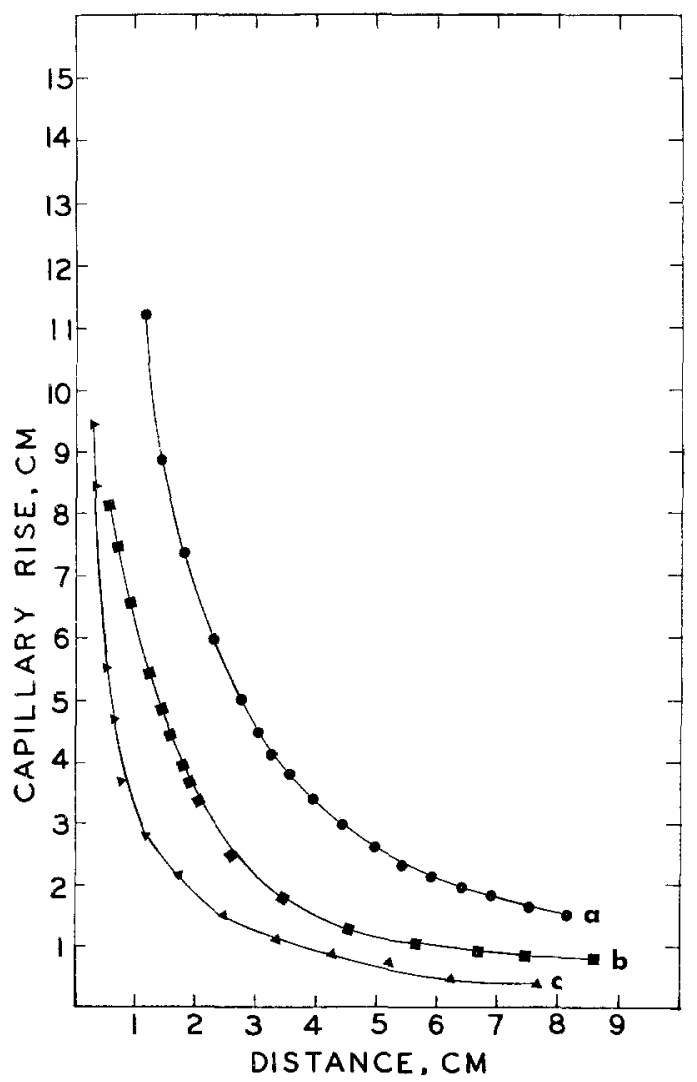

FIG. 5. Capillary rise eurves for: (a) glasswater-glass, $\overline{x h}=13.16$; $(b)$ silicone-water-glass, $\overline{x h}=6.35 ;(c)$ Teflon-water-glass, $\overline{x h}=3.32 \mathrm{sq}$ em. $\phi=38^{\prime}$.

mentioned coordinate cathetometer was used to measure the vertical height of the capillary curve from the vertex to within about $5 \mathrm{~mm}$ of the shim. The curve beyond

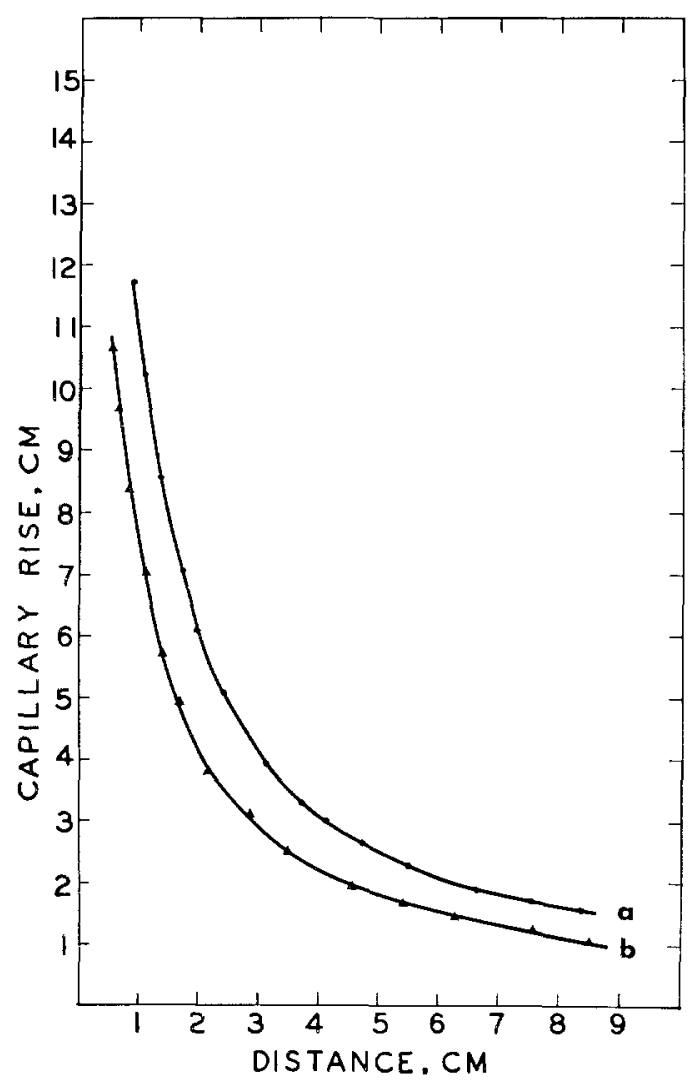

Fig. 6. Capillary rise curves for: $(a)$ glasswater-glass, $\overline{x h}=12.36 ;(b)$ glass-water-acrylic, $\overline{x h}=8.09 \mathrm{sq} \mathrm{cm}$. Both with $\phi=38^{\prime}$.

this point was influenced by the presence of the shim.

\section{RESULTS}

Parameters. Contact angles. The advancing and receding contact angles along with the number $n$ of replications are given in Table II. The values for water on acrylic agree with those of Craig, Berry, and Peyton (7). The mean values for water on Teflon are slightly lower, but within reasonable agreement with the values reported by Kawasaki (8). Silicone-coated glass exhibited an advancing contact angle value of $91^{\circ}$. As shown, the contact angle values of ethanol and iodobenzene are considerably lower than those of water on the same solids. Iodobenzene exhibited poorer wetting on glass than might be expected of an organic liquid. Ethanol, in contrast, spreads completely on 
glass. The pooled standard deviation for these data was calculated to be 6 degrees.

Surface tension. The surface tensions of ethanol, iodobenzene, and distilled water

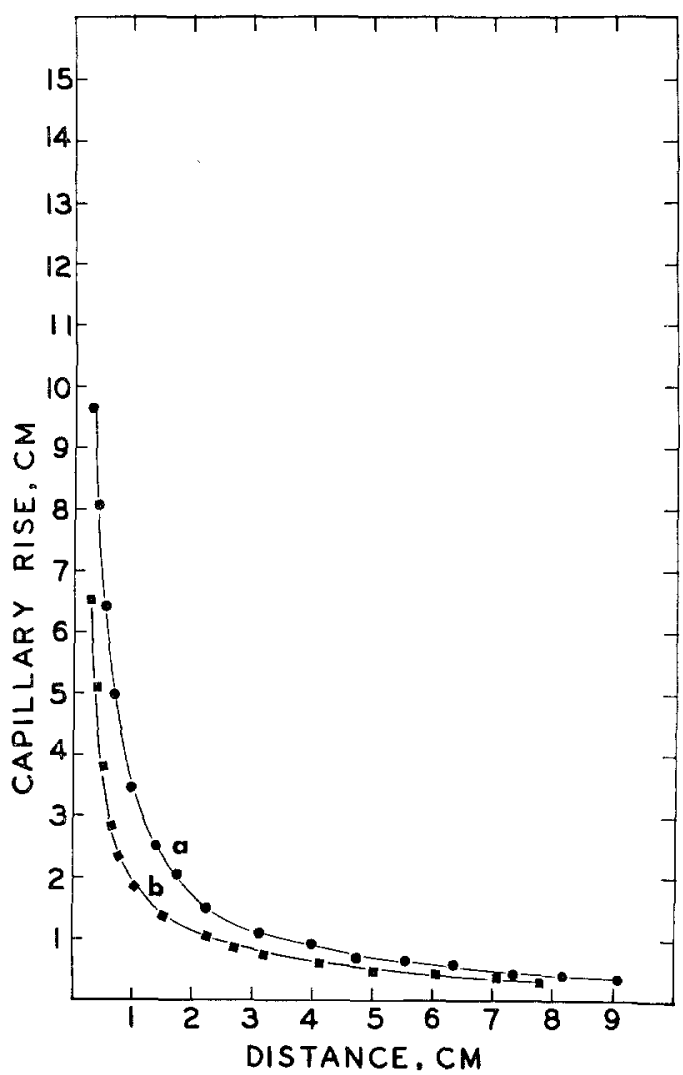

Fug. 7. Capillary rise curves for: (a) glassiodobenzene-glass, $\overline{x h}=3.37 \mathrm{sq} \mathrm{cm}$; $(b)$ Tefloniodobenzene-glass, $\overline{x h}=2.19 \mathrm{sq} \mathrm{cm} . \phi=3.8^{\prime}$. were found to be $22.3,39.1$, and 70.9 dynes per centimeter at $27^{\circ} \mathrm{C}$. Values reported in the literature (9) were 22.3, 39.7, and 71.6 dynes per centimeter.

Capillary rise. The capillary rise $h$ was measured at several distances $x$ from the vertex of the plates for the permutations given in the factorial table. The data are represented graphically as rise-distance curves. Each data point represents the height of the liquid above the liquid level in the trough. Figures 5 to 7 were selected to illustrate the results obtained.

Curves representing the rise obtained with three different combinations of plates are presented in Fig. 5. The rise curve obtained when two glass plates were used is the highest of the three. When a silicone-treated plate was substituted for one of the glass plates, the capillary rise was reduced to approximately one half that obtained with the two glass plates. Substitution of a Teflon plate produced the data for curve $c$ in Fig. 5 . This curve shows the lowest capillary rise of the three in Fig. 5.

Figure 6 shows the effect of substituting an acrylic plate. Here the rise with the glasswater-acrylic combination, curve $b$, is lower than the rise with the glass-waterglass system represented by curve a. As shown in Fig. 7, the rise of iodobenzene is reduced when a Teflon plate is used.

The mean observed $x h$ values for all the curves obtained are given in Table III.

TABLE III

Predicted and Observed $x h$ Values, in Square Centimeters

\begin{tabular}{|c|c|c|c|c|c|c|c|c|c|}
\hline \multicolumn{4}{|c|}{ Water } & \multicolumn{3}{|c|}{ Iodobenzene } & \multicolumn{3}{|c|}{ Ethanol } \\
\hline Glass & Teflon & Acrylic & Silicone & Glass & Teflon & Acrylic & Glass & Teflon & Acrylic \\
\hline \multicolumn{10}{|c|}{ Glass } \\
\hline $13.6^{a}$ & $4.20^{a}$ & $8.25^{a}$ & $6.84^{a}$ & $3.88^{a}$ & $2.92^{a}$ & $3.94^{a}$ & $5.26^{a}$ & $4.73^{a}$ & $\begin{array}{l}7.45^{\alpha} \\
7.55^{b}\end{array}$ \\
\hline $\begin{array}{l}13.2^{b} \\
12.6^{b}\end{array}$ & $3.32^{b}$ & $8.09^{b}$ & $\begin{array}{l}6.93^{b} \\
6.35^{b}\end{array}$ & $3.37^{b}$ & $2.20^{b}$ & $2.95^{b}$ & $5.45^{b}$ & $4.40^{3}$ & $\begin{array}{c}10.6^{a} \\
9.36^{b}\end{array}$ \\
\hline \multicolumn{10}{|c|}{ Acrylic } \\
\hline $7.01^{a}$ & $-0.70^{a}$ & $3.47^{a}$ & $4.04^{\alpha}$ & $3.94^{a}$ & $2.92^{a}$ & $3.88^{\circ}$ & $5.26^{a}$ & $4.73^{a}$ & $5.26^{a}$ \\
\hline $7.34^{b}$ & $0.00^{b}$ & $3.44^{b}$ & $3.81^{b}$ & $3.32^{b}$ & $2.82^{b}$ & $3.32^{b}$ & $5.05^{b}$ & $4.18^{b}$ & $4.08^{b}$ \\
\hline
\end{tabular}

a Predicted values.

¿ Mean observed values. 


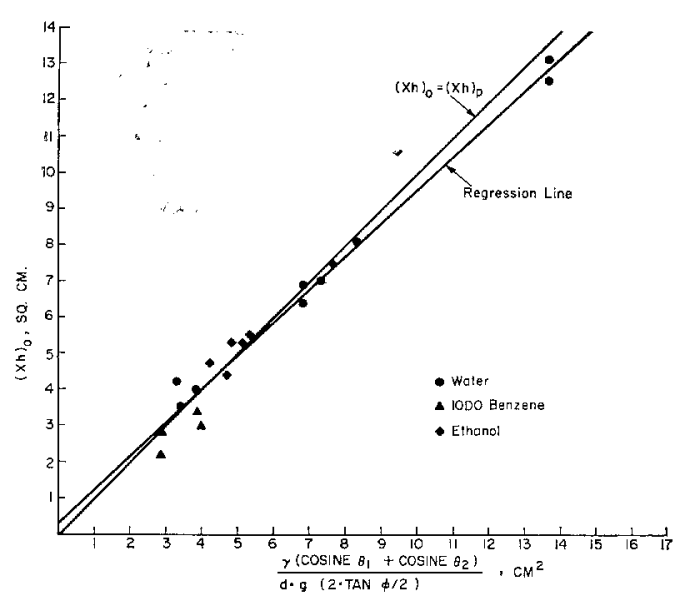

Fig. 8. Regression of observed $\overline{x h}$ values on calculated $x h$ values.

\section{EVALUATION OF THE MODEL}

In order to evaluate the newly derived mathematical model for liquid penetration between dissimilar plates, it is necessary to estimate its predictive ability. This may be done by substituting the values of the contact angles and surface tensions into the prime equation and solving for $x h$, the constant of the hyperbolic curve described by the meniscus of the liquid; then

$$
x h=\frac{\gamma_{L V}\left(\cos \theta_{1}+\cos \theta_{2}\right)}{2 d \tan \phi / 2} .
$$

The advancing contact angle values for the three liquids on acrylie, glass, Teflon, and silicone-treated glass along with the determined surface tensions and known densities $(0.79,1.82$, and $1.00 \mathrm{gm}$ per cubic centimeter for ethanol, iodobenzene, and water) were substituted in Eq. [13]. Following this procedure, the $x h$ values shown in Table IIT were calculated. These values were plotted against those obtained by experiment in Fig. 8.

Regression analysis. The first step in testing for the degree of association between the predicted and experimentally determined values, was to calculate the equation of the regression line that best fit the data points (10). With the use of the least squares method, the regression line for the observed values of $x h$ on the predicted values, $x h$ was found to be:

$$
(x h)_{o}=0.91(x h)_{p}+0.30 .
$$

TABLE IV

Analysis of Variance for Regression

\begin{tabular}{lccccc}
\hline $\begin{array}{l}\text { Source of } \\
\text { variance }\end{array}$ & $\begin{array}{c}\text { Sums of } \\
\text { squares }\end{array}$ & $\begin{array}{c}\text { Degrees of } \\
\text { freedom }\end{array}$ & $\begin{array}{c}\text { Mean } \\
\text { squares }\end{array}$ & $F$ \\
\hline Regression & 339 & 1 & 339 & 970 \\
Residual & 6 & 21 & 0.35 & \\
Total & 345 & 22 & & \\
\hline
\end{tabular}

Here the subscripts $o$ and $p$ refer to observed and predicted, respectively.

This line is drawn through the data in Fig. 8 along with the line,

$$
(x h)_{o}=(x h)_{p} .
$$

Figure 8 appears to contain fewer data points than is indicated by Table III owing to the coincident location of a few of the points. The regression analysis, however, was carried out with all the data given in this table.

The slope of the regression line, 0.91 , is close to unity indicating that the values $(x h)_{o}$ and $(x h)_{p}$ are close to being in a $1 / 1$ correspondence.

Correlation coefficient. The absolute magnitude of a slope may be tested for significance, but there is no way to decide from the value of the slope alone whether a correlation is strong or weak. The strength of the correlation may be defined as the fraction of the total variance that is due to regression. The correlation coefficient was computed for the data shown in Fig. 8 and found to be equal to 0.95 .

Therefore, the predicted values obtained with Eq. [13] correlated highly and significantly with the observed values in almost a $1 / 1$ ratio. In summary, the model appears to be satisfactory.

The error or unexplained variance may be due to errors in measurement of the parameter values or in the determination of the capillary rise. The greatest variation from the predicted values is found with systems containing Teflon. The most likely cause for this greater variation is the surface unevenness of the Teflon plates.

Another possible source of error is in the simplifying assumption that the weight of the meniscus above the lowest portion was 
insignificant. This assumption is also made in the derivation of the Young-Laplace equation.

\section{DISCUSSION}

The proposed equation [7] shows to what degree a liquid will penetrate between two solids, at equilibrium. This equation casts light on the relation between the wetting of two materials and capillary pressure. With the equation derived on the basis of the free energy change occurring at the solidliquid interface, no knowledge of the radius of curvature of the liquid-gas interface is necessary. This model teaches that the free energy change accompanying wetting is the driving force for capillary penetration. An examination of specific systems will illustrate this. Consider what occurs when water is allowed to penetrate between two glass plates. With the use of Eq. [3] the following is found:

$$
\begin{aligned}
\left(F_{S V}-F_{S L}\right)+\left(F_{S V}-F_{S L}\right) \\
=\Delta F s=\gamma_{L V}\left(\cos \theta_{1}+\cos \theta_{2}\right)
\end{aligned}
$$

or

$$
\Delta F s=-136 \mathrm{ergs} / \mathrm{cm}^{2} .
$$

This driving force produces the rise curve shown in curve $a$ of Fig. 5. A plot of $\Delta F s$ against the $(x h)$ values obtained with water and various combinations of plates in Fig. 9 illustrates the relationship between $\Delta F s$ and capillary rise.

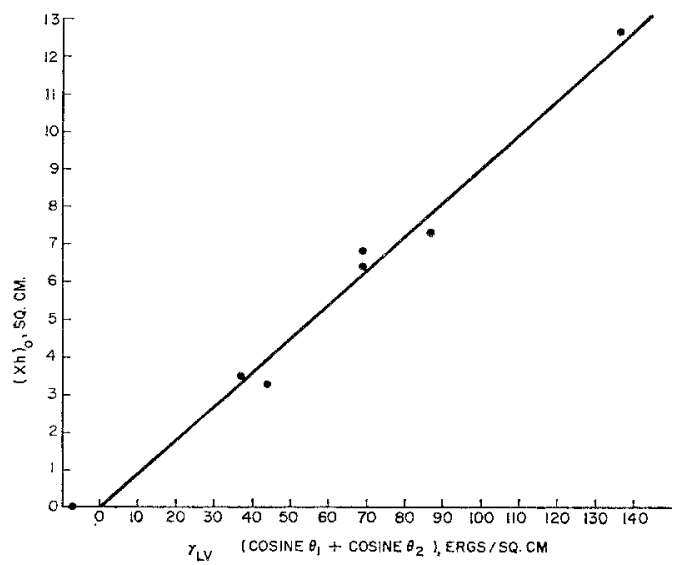

Fig. 9. Observed $\overline{x h}$ values versus interface free energy change per unit area for water.

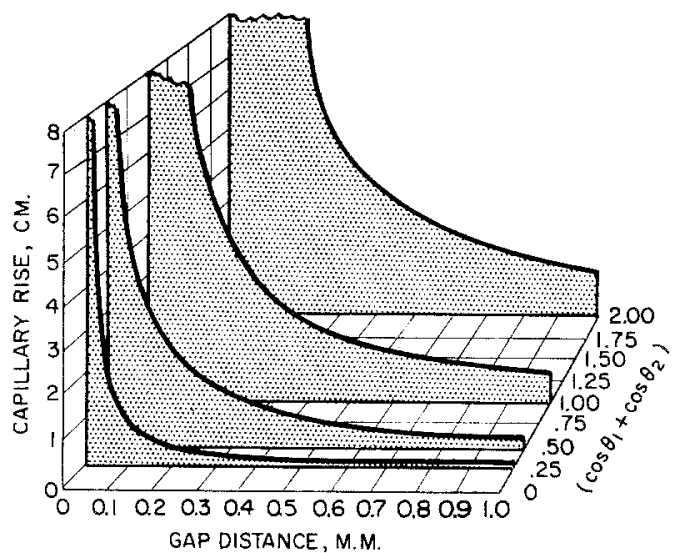

FIG. 10. Capillary rise curves for water between two plates for different $\left(\cos \theta_{1}+\cos \theta_{2}\right)$ values.

Iodobenzene and ethanol produced less marked effects than water. Curve $a$ in Fig. 7 is the capillary rise curve obtained with the system glass-iodobenzene-glass. Upon substitution of a Teflon plate for one of the glass plates, capillary rise curve $b$ was obtained. Compared with the water systems, there was a less marked decrease in rise. This is due to the lower contact angle between iodobenzene and Teflon. Figure 10 is a pictorial representation of the relation between capillary rise, gap distance, and the contact angles for water between two plates.

\section{SUMMARY}

The major purpose of this study was to develop and evaluate a mathematical model for the capillary penetration of a liquid between two dissimilar plates. Attempts have been made in the past to apply the Young-Laplace equation to this situation, but without success because of the complex curvature of the meniscus. Instead, free energy considerations were used to derive the proposed equation. The equation obtained for the capillary rise $h$ for a liquid of surface tension $\gamma_{L V}$ into a space $b$ between two plates whose contact angles with the liquid are $\theta_{1}$ and $\theta_{2}$ was found to be:

$$
h=\frac{\gamma_{L V}\left(\cos \theta_{1}+\cos \theta_{2}\right)}{b d g},
$$

where $d$ is the liquid density and $g$ is the gravitational constant. 
Experimental values of capillary penetration between combinations of three liquids and several solids were obtained with the use of the hyperbola method. A factorial design was employed. These data were compared with those predicted by means of the proposed equation. Regression, correlation, and analysis of variance were used to test for the degree and significance of the association between the predicted and observed values. These results and a dimensional analysis indicate that the proposed equation is satisfactory.

\section{REFERENCES}

1. Adamson, A. W., "Physical Chemistry of Surfaces," pp. 4-6. Wiley, New York, 1960.

2. BAKKER, G., "Kapillarchemie," In "Handbuch der Physik." Vol. VI, pp. 71-83. WienHarmsschen, Leipzig, 1928.

3. WoLf, K. L., "Physik und Chemie der Grenzflachen. Springer, Berlin, 1957.
4. Schwartz, A. M., And Minor, F. W., “A Simplified Thermodynamic Approach to Capillarity," J. Colloid Sci. 14, 572-583 (1959).

5. Grunmach, Leo, "Über einen neuen Plattenapparat yur Bestimmung von Kapillaritatskonstaten nach der Steighohenmethode," Physik. Zeit., ZI: 980-989, 1910.

6. Macdougall, G., and Ockrent, C., "Surface Energy Relations in Liquid Solid Systems," Proc. Roy. Soc. London 180A, 151-173 (1941).

7. Craig, R. G., Berry, G. C., and Peyton, F. A., "Physical Factors Related to Denture Retention," J. Pros. Dent., 64, 541-543 (1960).

8. KAWASAKI, K., "Study of Wettability of Polymers by Sliding of Water Drops," $J$. Colloid Sci. 15, 402-407 (1960).

9. Hodgemen, C. D., ed., "Handbook of Chemistry and Physics," 44th ed., p. 2233. Chemical Rubber Publishing Co., Cleveland, 1962.

10. Steel, R. G., and Torrie, J. H., "Principles and Procedures of Statistics," p. 107. McGraw-Hill, New York, 1960. 